\title{
An Econometric Analysis of World GDP Share of India during 1960-2015
}

\section{Debesh Bhowmik}

PhD, Retired Principal and Associated with The Indian Econometric Society, India

\begin{abstract}
In this paper author attempted to analyse India's international GDP share during 1960-2015 with the help of econometric models taking the data from the World Bank. Semilog linear trend model and exponential trend model were used to find the trend of growth. Variance ratio test was used to show random walk. AR(1) model was used to show stationary, convergence and oscillations. ARIMA $(1,1,1)$ model was tested for the stationary of the series. Forecast for 2035 of the AR(1) and ARIMA(1,1,1) models verified stationary long term patterns. Bai-Perron (2003) model explained to show structural breaks and the study of Bartoletto, Chiarini, Marzano \& Piselli (2015) was followed to compute peaks, troughs, durations of cycles, amplitudes and slopes of both the short and medium cycles during 1960-2015. Hodrick-Prescott Filter (1997) model minimized the cycles for smoothness of trend of GDP share. The paper concludes that international GDP share of India has decreased at the rate of $0.459 \%$ per year during 1960-2015 and declined exponentially at the rate $0.259 \%$ per year significantly. The growth rate of the GDP share is downward sloping significantly till 2030 . It follows random walk without drift. Its AR(1) is stable, convergence and stationary. Forecast for 2035 of $\operatorname{AR}(1)$ is also converging. ARIMA $(1,1,1)$ is stable and non-stationary and suffers from AC and PAC problems. Its forecast model for 2035 is tending towards stationary insignificantly. GARCH $(1,1)$ showed excessive volatility. It has two downward structural breaks in 1968 and 1988 and one upward break in 2006 which are significant. The paper verified short and medium cycles to calculate peaks and troughs, duration of downturn and upturn, amplitude and slope of the cycles respectively. HP filter model makes the cycle more smooth with only one trough assuming lamda comprises 1600 but symmetric and asymmetric filter showed two peaks and two troughs. The frequency response function clarified its peaks and amplitude of cycle clearly.
\end{abstract}

Keywords: international GDP share, exponential growth, structural break, non-stationary, HP filter, peaks, trough.

JEL Classification: N13, N15, O21, O24, O57, O10.

(C) The Author, 2018. This article is published with open access at Sumy State University.

\section{Introduction}

The world's GDP share of India is an important indicator which can explain the nature of Indian economic development in comparison to other international economies. During ancient past of economic development of India, it was evident that India's world GDP share was highest till 1500 AD and India was the dominant country. During 1500-1650, China was dominant followed by India, and then during 1650-1750, India was dominant followed by China. Since 1870, the world scenario changed rapidly due to rise in western civilization and industrial revolution where Europe was the dominant country and India and Chinese GDP started to decline rapidly. After the First and the Second World Wars, USA's dominance in trade, finance and commerce outweigh UK dominance and USA became the largest GDP share holder in the world up till now. And India's share has been falling till 1993, and then upswing started in but it is too little in comparison to other nations. During $1 \mathrm{AD}$, India's share was $33 \%$,followed by $30 \%$ in $1000 \mathrm{AD}, 24 \%$ in $1500-1700 \mathrm{AD}, 17 \%$ in $1820 \mathrm{AD}, 7 \%$ in 1913 , and now it is $2.79 \%$ in 2015 respectively. But, within 2025 , China will recover his previous historical dominance in terms of GDP in the world. In Figure 1, India, China and other nations' world GDP shares are plotted during 1AD-2008AD for comparative study. 


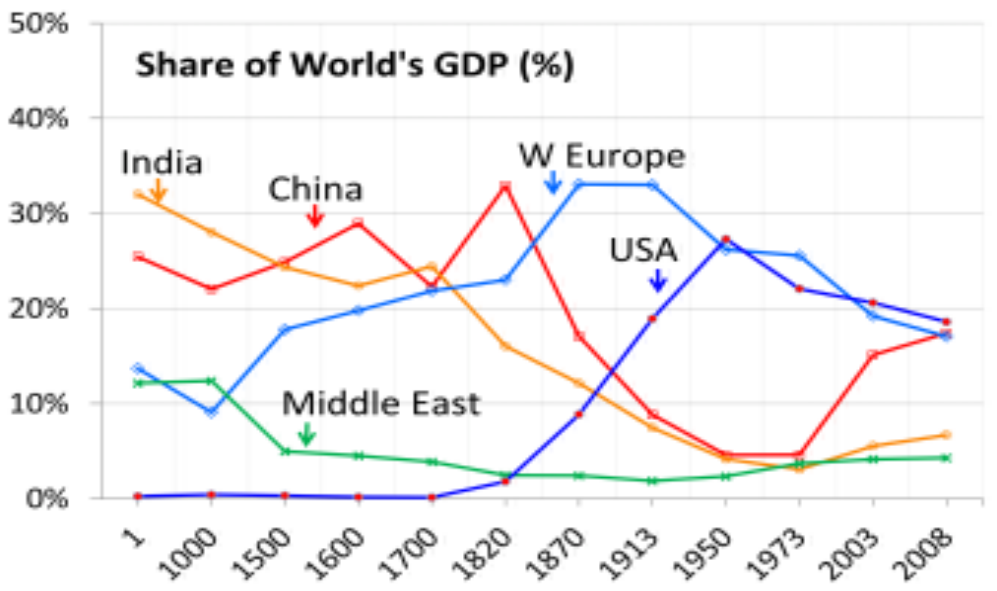

Figure 1. Share of world's GDP (\%)

Source: plotted by author.

According to economic historian Angus Maddison's book titled "The World Economy: A Millennial Perspective, India" was the richest country in the world and had the world's largest economy until the 17th century AD. During the Mughal period (1526-1858), the gross domestic product of India was estimated at about $25.1 \%$ of the world economy. The estimation of India's pre-colonial economy puts the annual revenue of Emperor Akbar's treasury in 1600 at $£ 17.5$ million (in contrast to the entire treasury of Great Britain two hundred years later in 1800, which totaled $£ 16$ million). The gross domestic product of Mughal India in 1600 was estimated at about $24.3 \%$ of the world economy, the second largest in the world.

By the late 17th century, the Mughal Empire was as its peak and had expanded to include almost $90 \%$ of South Asia, and enforced a uniform customs and tax-administration system. In 1700 the exchequer of the Emperor Aurangzeb reported that India earned annual revenue of more than $£ 100$ million.

PWC (Price Waterhouse Coopers) projected India's GDP for 2050 and indicated that even more significant changes could be ahead. PWC expects China to have GDP of $\$ 61$ trillion (US\$2014). India is projected to be restored to its previous second place, at $\$ 42$ trillion, just ahead of the United States ( $\$ 41$ trillion). By 2050, the E7 economies could have increased their shares of world GDP from around 35\% to almost 50\%. China could be the largest economy in the world, accounting for around 20\% of world GDP in 2050, with India in second place around 15\% followed by USA comprising 12\% share of the world and Indonesia is in fourth place (based on GDP at PPPs). They project Vietnam, India and Bangladesh to be three of the world's fastest growing economies over this period. By another forecast estimates it is pointed out that India's share in world output is projected to jump from $5 \%$ as of today to $20.8 \%$ by 2040 as per one estimate. PWC also estimated that during 2016-2050, India's population will grow at the rate of $0.7 \%$, and GDP growth rate will be $4.9 \%$ respectively. In context of India's GDP growth rate, it was observed that the average India's GDP growth rate was $0.38 \%$ during $1820-1870,0.97 \%$ during $1870-1913$ and $0.23 \%$ during $1913-1950$ respectively. On an average, the Indian economy grew at about 1\% per year from 1880 to 1920.

Therefore, the author intended to study the nature of India's share in world GDP from 1960-2015 through econometric models to find significant knowledge about its role on the economic development in the Indian economy.

\section{Literature review}

There are a few researches on India's world GDP share for analyzing growth. However, many academicians have explained the process of growth and GDP trend with econometric models. Agarwal and Ghosh (2015) performed structural break analyses of several macroeconomic variables for the Indian economy to have a clear picture about the evolution of the economy from various dimensions, analyzing the components of GDP, interestingly, though GDP and GDP per capita series exhibit of multiple structural breaks, they do not find any statistically significant structural break in the Indian GDP growth rate. Papola (2012) highlighted the major structural aspects of India's economic growth specially over the past three decades from the viewpoint of its long-term sustainability. It reviews the trends in sectoral patterns of GDP growth, employment, 
trade, industry and inter-regional and inter-class disparities and brings out implications of these trends for a sustainable and equitable growth. Dua and Banerjee (2012) described business and growth rate cycles with special reference to the Indian economy. They used the classical NBER approach to determine the timing of recessions and expansions in the Indian economy, as well as the chronology of growth rate cycles, viz., the timing of speedups and slowdowns in economic growth. They showed peaks and trough as well as recession and expansion since 1960. Dua and Banerji (1999) showed that, over the last four decades, India has experienced six business cycle recessions characterized by pronounced, pervasive and persistent declines in output, income, employment and trade. Mohanty, Singh and Jain (2003) verified that the cyclical behaviour of the Indian economy showed that the economy has transited through thirteen growth cycles of various amplitudes and periodicity during the last three decades with average duration of cycle approximating 27 months. While the recessions persist for the average duration of 16 months, the expansion phase is of relatively shorter duration averaging 12 months. This is in contrast to the general proposition that expansionary phase in the business cycle is larger than the contractionary phase. Virmani (2005) using HP filter series showed two phases of growth rate such as 1971-1974 (3.3\%) and 1994-1996 (6.1\%) and there is clear break in mean and coefficient of variation if phase one ends in 1978-1979 (phase-1 from 1950-1951-1978-1979, and phase 2 from 1978-1979 to 2002-2003). It was verified that 45\% variation of India's GDP growth is explained by fluctuations in rainfall during 1950-2002 with a break in 1980-1981 and there is no break in the effects of rainfall on the growth rate from 1980-1981 onwards. Nayyar (2008) attempts to analyse the economic implications of the rise of China, India, Brazil and South Africa, for developing countries situated in the wider context of the world economy. It considers the main channels of transmission, to focus on international trade, investment, finance and migration. The rapid growth in these large emerging economies is already beginning to change the balance of economic power in the world. Wolf, Larson \& Huang (2011) assess the prospects of India and China through 2025 in four domains: demography, macroeconomics, science and technology, and defense spending and procurement. They try to assess the balance between advantages and disadvantages that China and India will possess 15 years hence. This balance is relevant for potential cooperation between the two countries, no less than for their potential competition and rivalry. They repeatedly acknowledge the uncertainties created for the assessment by such qualitative unknowns as whether or not each country may encounter internal civil unrest, political disruption, external conflict, or natural disasters. In addition to those, Nayyar (2008), Paul \& Mas (2016) and Wolf, Larson \& Huang (2011) discussed about Indian and Chinese role in the world economy.

\section{Data and methodology}

The data of India's GDP and world GDP have been collected from the World Bank from 1960 to 2015. The linear and exponential trends have been computed by semilog linear and exponential regression models. The forecast for 2035 trend line was also calculated. Variance ratio test was used to verify random walk of the model. AR(1), ARIMA $(1,1,1)$ models were used to compute stationary, stability and convergence of the models. AR(1) forecast model for 2035 were also applied here to check stationary. $\operatorname{ARIMA}(1,1,1)$ forecast for 2035 model was used to tend the system into stationary. Bai-Perron (2003) model was used to verify the structural breaks of the system and HP filter (1997) model was taken to modify the cyclical trend into smooth cycle whether it is symmetry or asymmetry. The study of Bartoletto, Chiarini, Marzano, \& Piselli (2015) was followed to compute peaks, troughs, durations of cycles, amplitudes and slopes of both the short and medium cycles during 1960-2015. Assume, $y$ is India's world GDP share, $t$ is the year.

\section{Econometric observations}

World's GDP share of India has been declining at the rate of $0.459 \%$ per year during 1960-2015 significantly. The estimated trend line through semi-log linear regression model is given below.

$\log (y)=0.7538-0.00459 t$

$$
(10.61)^{*}(-2.12)^{*}
$$

$R^{2}=0.07, F=4.50 *, D W=0.1133, *=$ significant at $5 \%$ level.

where $Y$ is India's international GDP share (\%), $t$ is the year.

In Figure 2, the declining fitted trend line is plotted clearly. It is shown below. Besides, the actual trend of $\log (y)$ has clear downward movement with some expansions and contractions before 1992 and then it shows steady upward trend. 


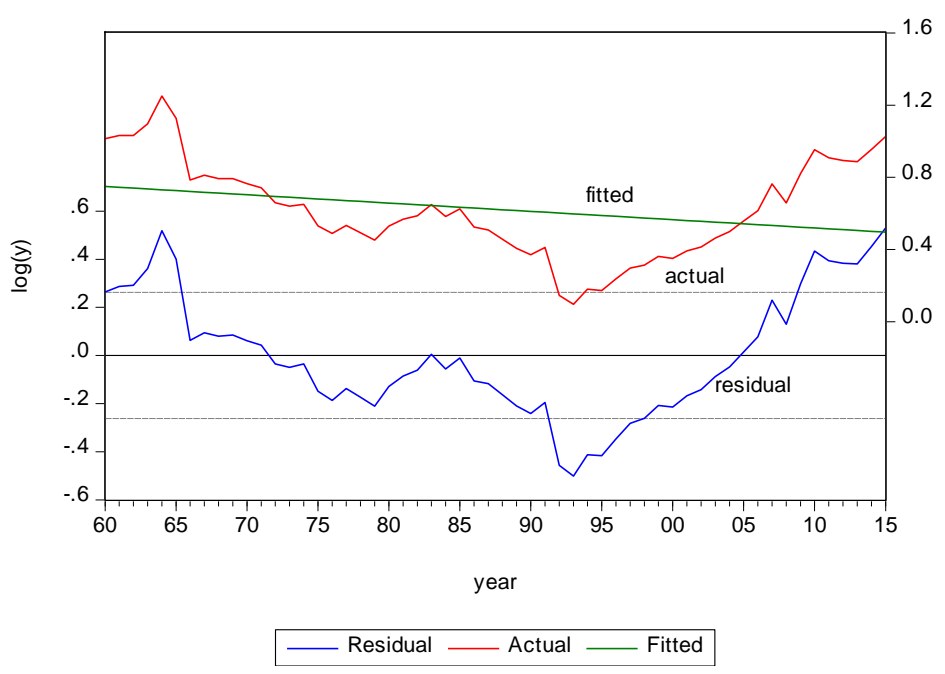

Figure 2. Trend line

Source: plotted by author.

The forecast model of $\log (y)=0.7538-0.00459 t$ for 2035 has been declining significantly which is seen in Figure 3.

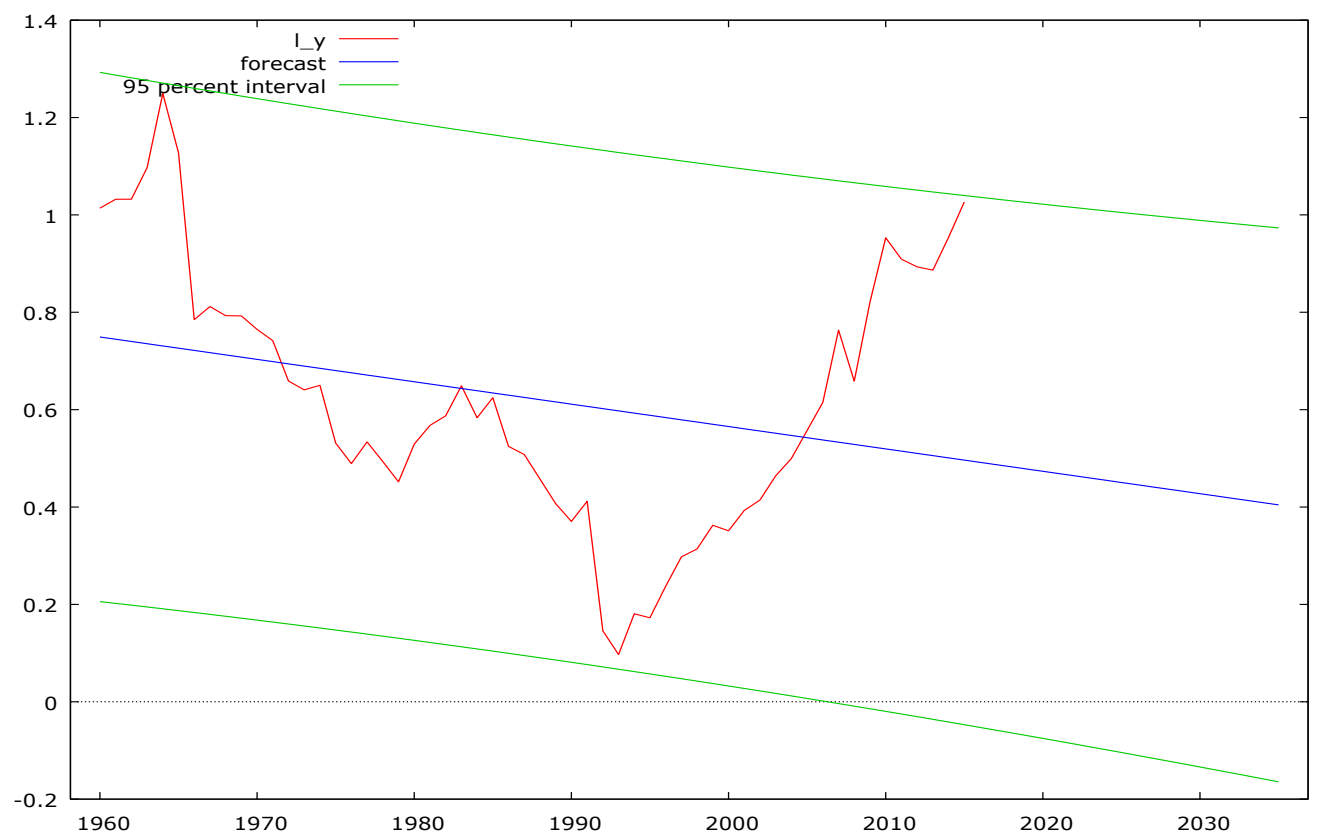

Figure 3. Forecast for 2035

Source: plotted by author.

Actually, the world's share of GDP of India during 1960-2015 follows exponential relation which states that the share has been decreasing exponentially at the rate of 0.259 per cent per year which is significant at $5 \%$ level. The estimated equation is given below.

$\mathrm{y}=e^{0.18776+t^{-0.259298}}$

The $t$ values of 0.18776 and -0.259298 are 1.6311 and -2.888 respectively. The estimated exponential trend line is plotted below. 


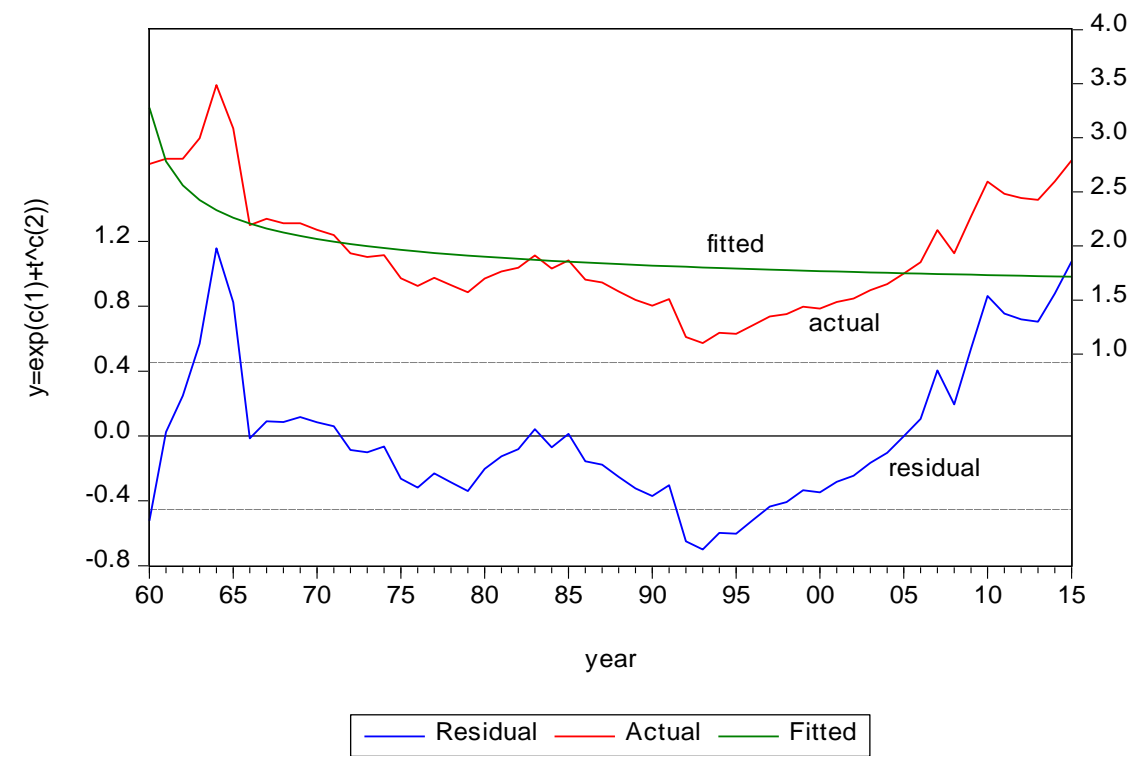

Figure 4. Exponential series

Source: plotted by author.

Assume $x=\left(y_{t}-y_{t-1}\right) /\left(y_{t-1}\right) \times 100=$ percentage change of India's international GDP share $=$ growth rate $(\%)$, then the estimated value of $\log x$ is given below.

$\log (x)=0.00936811-0.0097803 \mathrm{t}$

$(0.0506) \quad(-1.749)$

$R^{2}=0.0545, F=3.06, D W=0.149$.

The estimation is not a good fit because of very low $R^{2}$ and $F$. The estimated equation states that the growth rate of India's World GDP share is declining steadily at the rate of $0.978 \%$ per year insignificantly during 1960-2015 which is also plotted in Figure 5.

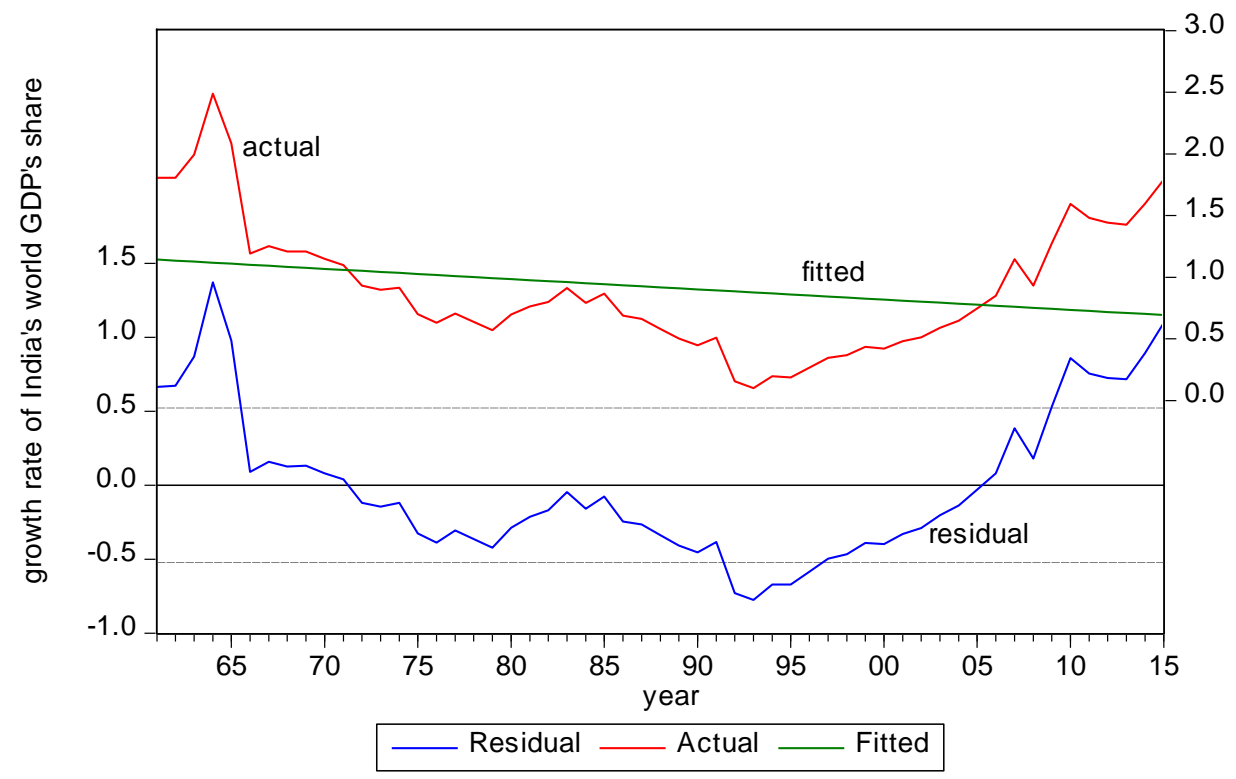

Figure 5. Growth rate of GDP share

Source: plotted by author.

The above forecast model states that the growth rate of India's world share of GDP will decrease at the rate of $68.50 \%$ in 2030 as forecasted by this estimated line which is shown in Figure 6. 


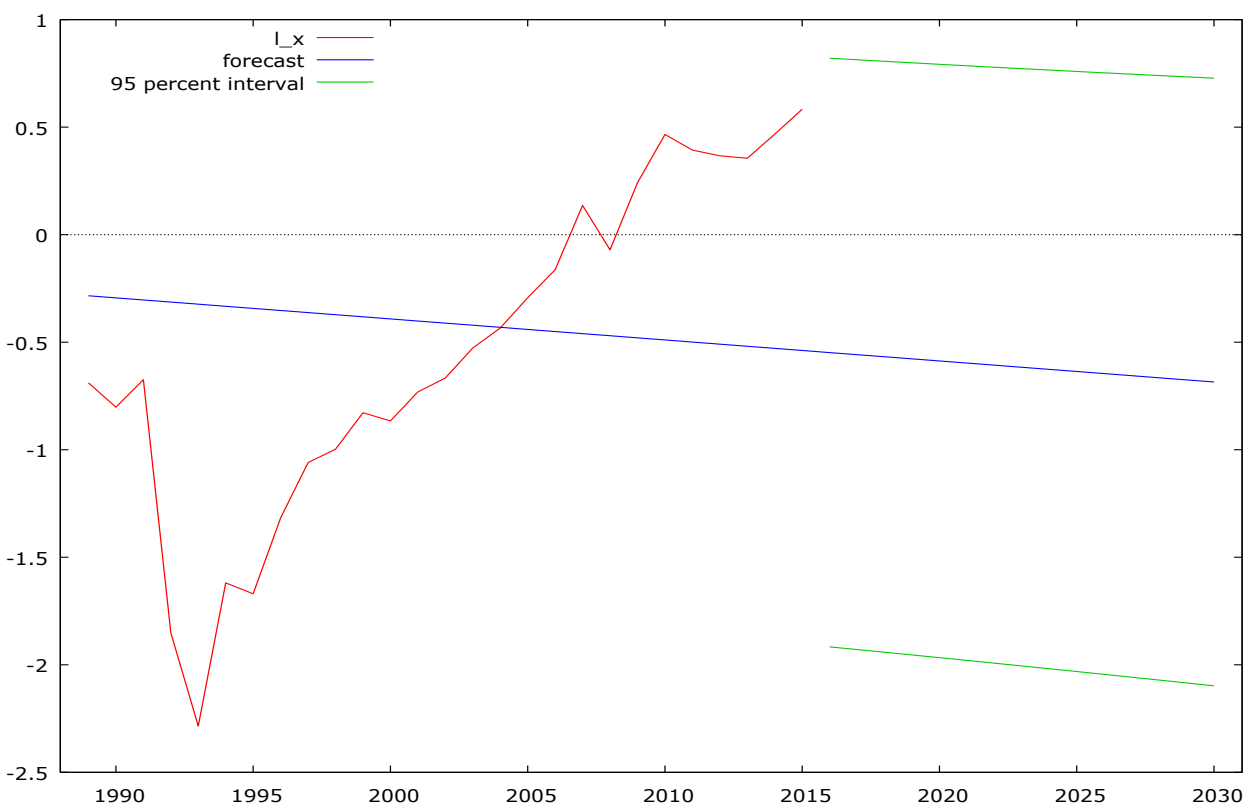

Figure 6. Forecast of growth of share for 2030

Source: plotted by author.

The world's GDP share of India during 1960-2015 follows random walk as suggested by variance ratio test where joint test and individual test of z statistic are insignificant. The Null Hypothesis $\mathrm{H} 0=\log (\mathrm{y})$ is martingale and is rejected. Their values are shown in Table 1.

\section{Table 1. Variance ratio test}

Null Hypothesis H0: $\log (y)$ is martingale, lags specified as grid, $\min =2, \max =16$, step $=1$

\begin{tabular}{|c|c|c|c|c|}
\hline \multicolumn{2}{|c|}{ Joint test } & Value & Df & Probability \\
\hline Max $|\mathrm{Z}|$ at period15 & 2.189 & 55 & 0.35 \\
\hline \multicolumn{5}{|c|}{ Individual test } \\
\hline Period & Variance ratio & SE & z-statistic & prob \\
\hline 2 & 1.112 & 0.148 & 0.753 & 0.45 \\
\hline 3 & 1.101 & 0.225 & 0.452 & 0.65 \\
\hline 4 & 1.198 & 0.279 & 0.709 & 0.47 \\
\hline 5 & 1.289 & 0.317 & 0.909 & 0.363 \\
\hline 6 & 1.411 & 0.346 & 1.185 & 0.144 \\
\hline 7 & 1.541 & 0.370 & 1.460 & 0.110 \\
\hline 8 & 1.625 & 0.391 & 1.579 & 0.069 \\
\hline 9 & 1.744 & 0.409 & 1.815 & 0.049 \\
\hline 10 & 1.837 & 0.426 & 1.965 & 0.035 \\
\hline 11 & 1.926 & 0.441 & 2.098 & 0.030 \\
\hline 12 & 1.986 & 0.456 & 2.162 & 0.032 \\
\hline 13 & 2.007 & 0.469 & 2.144 & 0.030 \\
\hline 14 & 2.046 & 0.482 & 2.168 & 0.028 \\
\hline
\end{tabular}

Source: calculated by author.

But it follows random walk without a drift because coefficients are not significant where the estimate is calculated by the method of least squares with Gauss-Newton/Marquardt steps.

$d \log \left(y_{t}\right)=-0.028429-0.022965 \log \left(Y_{t-1}\right)+0.001476 t$

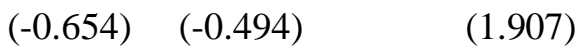

$R^{2}=0.0895, F=2.557, A I C=-2.023, S C=-1.914, D W=1.96$ 
But the model is not stable because the coefficient -0.022965 for confidence ellipse does not lie within the confidence limit but other's lie in the confidence limit of 5\%. It is shown in the Figure 7.

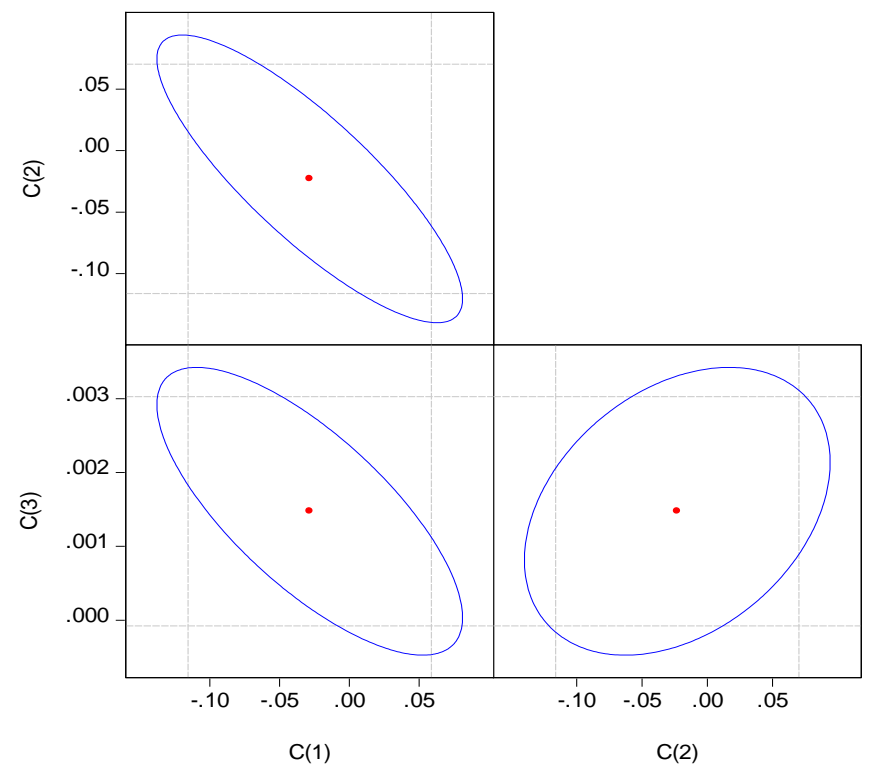

Figure 7. Confidence ellipse

Source: plotted by author.

Auto Regression (1) of India's GDP share is estimated below which is significant at 5\% level. This model is stationary, stable and convergent.

$\log y_{t}=0.798+0.9569 \log y_{t-1}+0.0074 \sigma^{2}$

$$
(3.046) *(25.36) *(7.79) *
$$

$R^{2}=0.89, F=229.59 *, D W=1.77, S C=-1.80, A I C=-1.91$, AR root $=0.96, *=$ significant at $5 \%$ level.

The solution of the above estimated equation is given below.

$\log Y_{t}=Y^{*}+(0.95)^{t} y_{0}$

If $\mathrm{t}$ tends to infinity then $\log Y_{t}$ tends to equilibrium $Y^{*}$, which is convergent and stationary where $Y^{*}=1.86$ and $\sigma^{2}=1$ and $y_{0}$ is initial income.

The forecast fitted model of Auto Regression (1) for 2035 is calculated as shown below. $\log y_{t}=0.798+0.9569 \log y_{t-1}+0.0074 \sigma^{2}$.

This estimated forecast line is moving towards stationary level as shown in Figure 8.

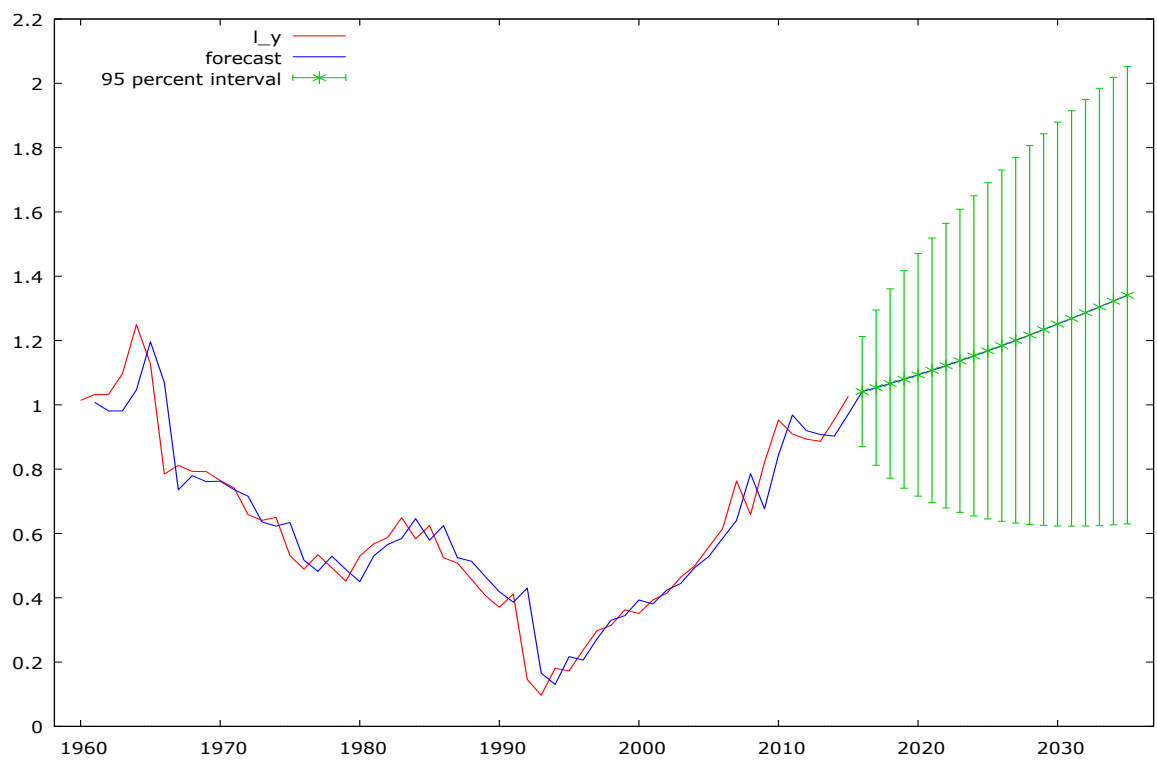

Figure 8. Forecast AR(1)

Source: plotted by author. 
The estimated ARIMA $(1,1,1)$ model showed that Auto Regressive process is significant but Moving Average process is insignificant whose coefficients confirmed that it is non-stationary, stable and divergent. The estimated equation is given below.

$\log Y_{t}=0.776+0.9453 \log Y_{t-1}+\epsilon_{t}+0.12975 \epsilon_{t-1}+0.00733 \sigma^{2}$

$$
(3.39) *(21.45)^{*} \quad(1.10) \quad(7.36) *
$$

$R^{2}=0.89, F=152.20^{*}, D W=1.97, A R$ root $=0.95, M A$ root $=-0.13, *=$ significant at $5 \%$ level.

Yet, the ARIMA $(1,1,1)$ forecast model for 2035 is moving towards stationary level which is plotted in Figure 9.

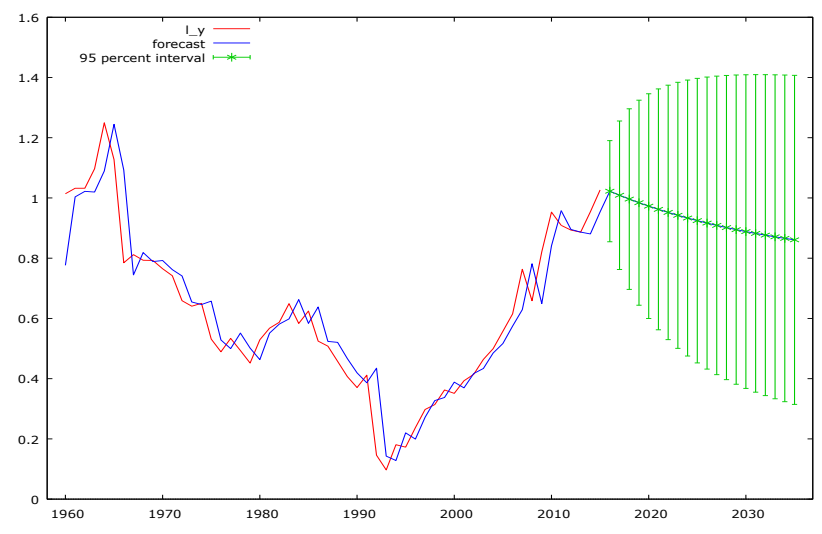

Figure 9. ARIMA forecast model

Source: plotted by author.

The residual test for ARIMA $(1,1,1)$ model suffers from Auto Correlation and Partial Auto Correlation problems which are confirmed by Figure 10 where the ACF and PACF are not declining uniformly. This also confirms that $\operatorname{ARIMA}(1,1,1)$ model is non-stationary.
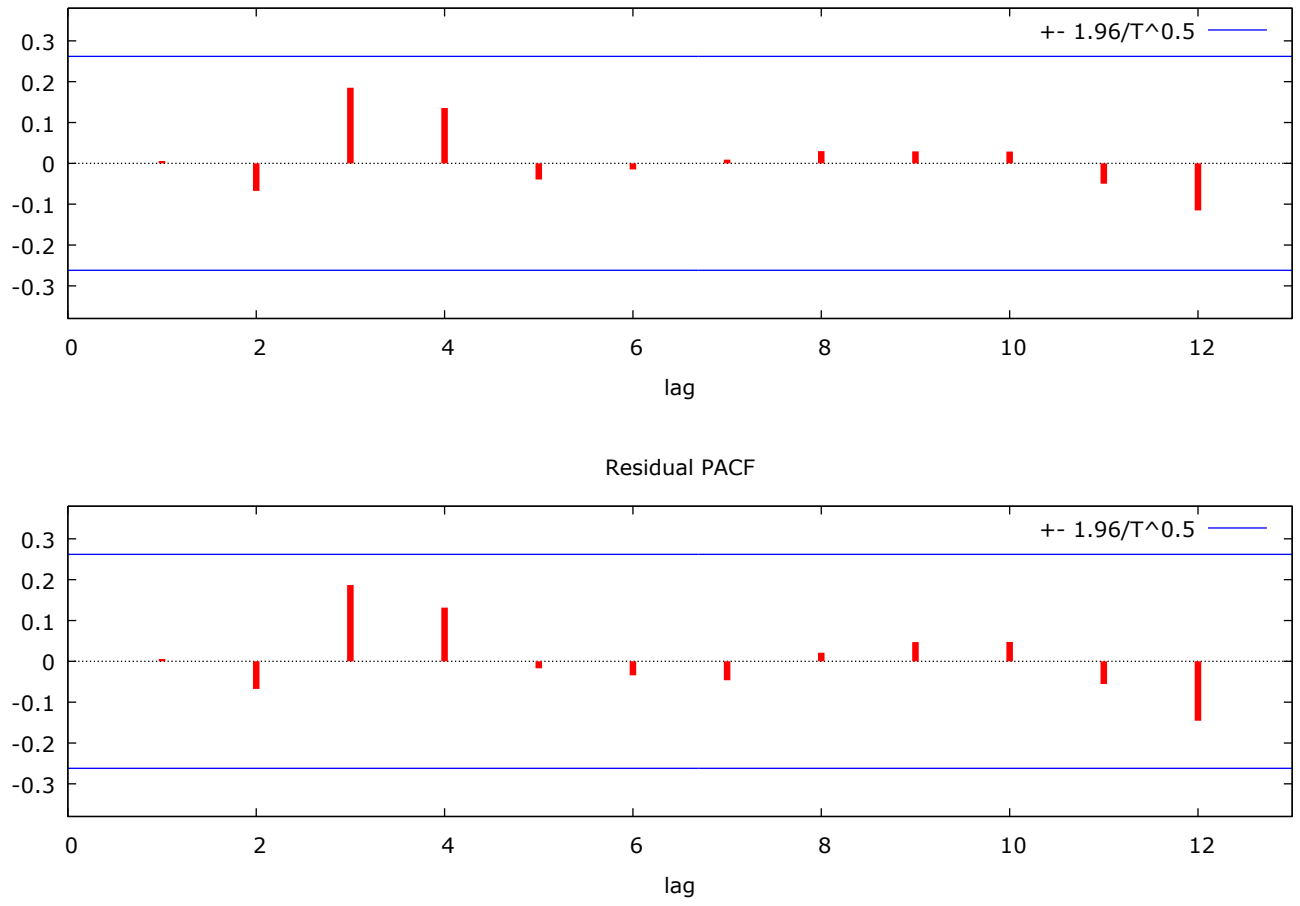

Figure 10. AC and PAC problems

Source: plotted by author.

The ARIMA $(1,1,1)$ model is stable since two roots are less than one and they reside inside the unit circle which is shown in Figure 11. 
Inverse Roots of AR/MA Polynomial(s)

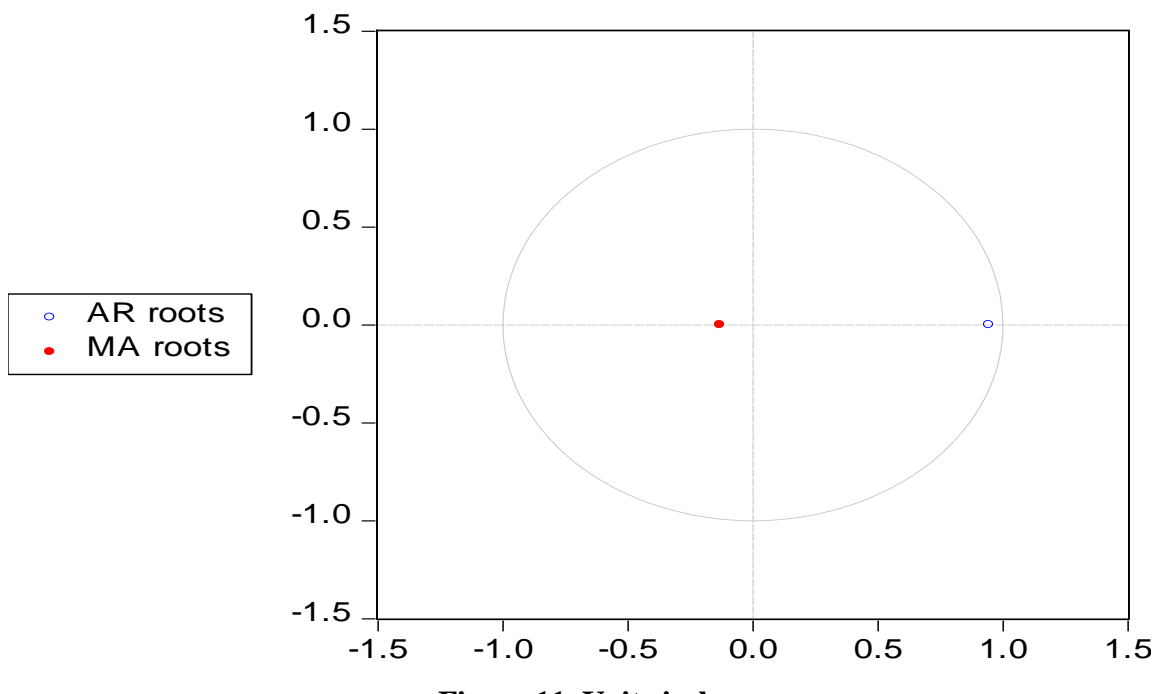

Figure 11. Unit circle

Source: plotted by author.

Both the Impulse Response Functions have been tending towards divergent and nonstationary level due to external shocks. It is plotted in Figure 12.

Response to One S.D. Innovation

Impulse Response \pm 2 S.E.

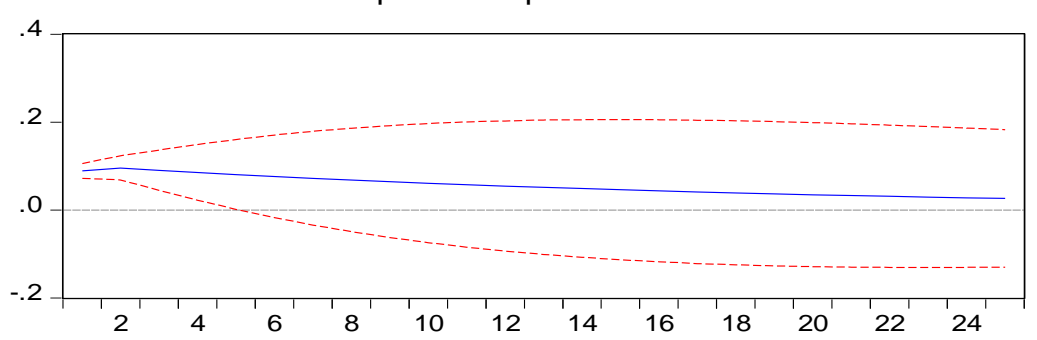

Accumulated Response \pm 2 S.E.

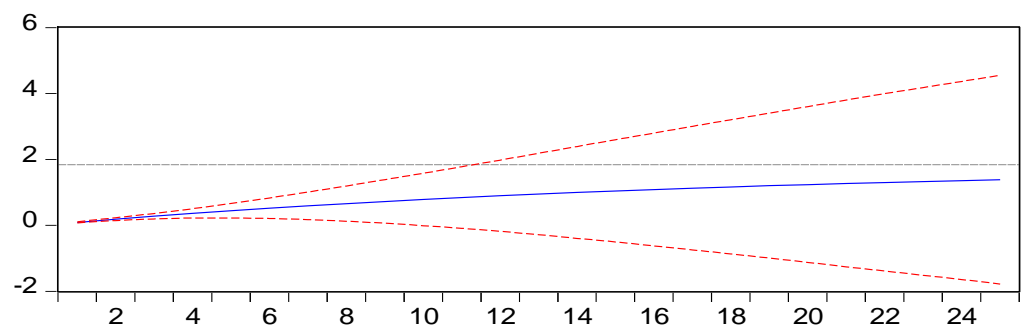

Figure 12. Impulse response functions

Source: plotted by author.

The world's share of GDP of India during 1960-2015 contains excessive volatility as shown by the estimated GARCH $(1,1)$ model which is given below.

$\sigma_{t}^{2}=0.019797+1.148241 h_{t-1}^{2}-0.18379 \sigma_{t-1}^{2}$

(0.092) (0.39069) (-0.0759)

$R^{2}=-5.405, D W=0.016, A I C=1.8123, S C=1.9208, h_{t}=$ conditional variance, $\sigma^{2}=$ variance

Since all the $z$-statistic of the coefficients of $\operatorname{GARCH}(1,1)$ are insignificant then excessive volatility is proved by this estimated model. The volatility is shown with the help of conditional variance as observed in Figure 13. The cyclical behavior of India's International GDP share is fully supported by this conditional variance. 


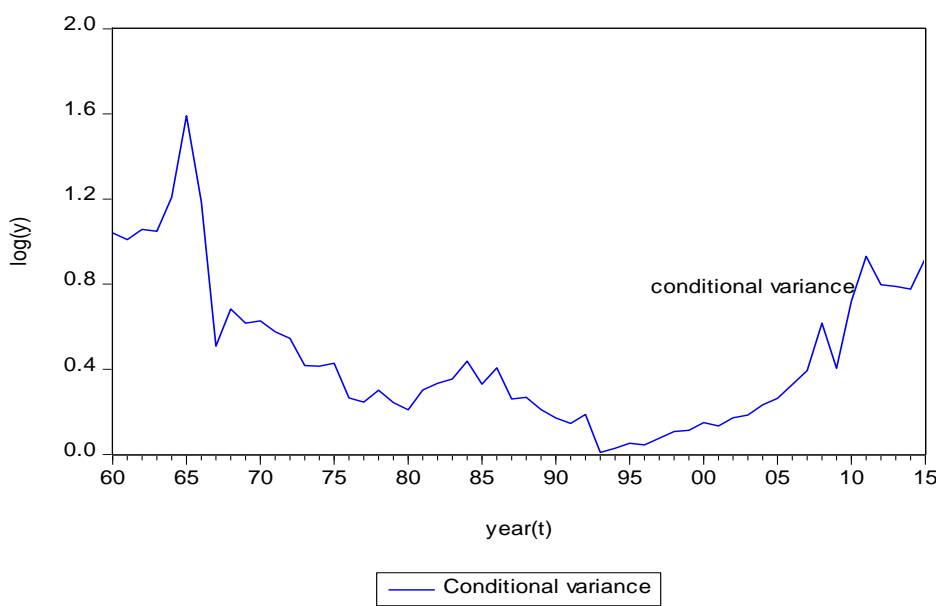

Figure 13. Conditional variance

Source: plotted by author.

Bai-Perron(2003) test verified that India's GDP share has three distinct structural breaks in 1968,1988 and 2006 respectively which are significant. In Table 2, the values of coefficients, standard error, $t$-statistic and probability have been arranged.The first two structural breaks are downward and the third one is upward. The test assumed $L+1$ vs $L$ sequentially determined breaks which was found significant at $5 \%$ level and sequential $F$-statistic of break test are significant for those three breaks. HAC standard errors and covariance (Bartlett Kernel, Newey-West fixed bandwidth $=3.0$, Trimming 0.15) technique was applied.

Table 2. Structural breaks

\begin{tabular}{|c|c|c|c|c|}
\hline Variable & Coefficients & Standard error & t-statistic & Probability \\
\hline & & $1960-1967=8 \mathrm{obs}$ & & 0.00 \\
\hline$C$ & 1.0186 & 0.0543 & 18.75 & 0.00 \\
\hline$C$ & & $1968-1987=20 \mathrm{obs}$ & & 0.00 \\
\hline$C$ & 0.6057 & 0.0396 & 15.27 & 0.00 \\
\hline$C$ & 0.3407 & $1988-2005=18 \mathrm{obs}$ & & 6.8208 \\
\hline & & 0.0499 & & 14.615 \\
\hline & 0.8480 & $2006-2015=10 \mathrm{obs}$ & $S C=-1.09, D W=0.99$ \\
\hline
\end{tabular}

Source: calculted by author.

In Figure 14, two downward structural breaks in 1968 and 1988 and one upward structural break in 2006 have been plotted clearly through estimated break line. Now, it is clear that the world's share of GDP of India during 1960-2015 contains cyclical behavior which showed that it has clearly 9 peaks and 8 troughs which are visible in the Figure 15 when the cycles are considered in the concept of both short and medium cycles respectively. The axioms of short and medium cycles are listed below.

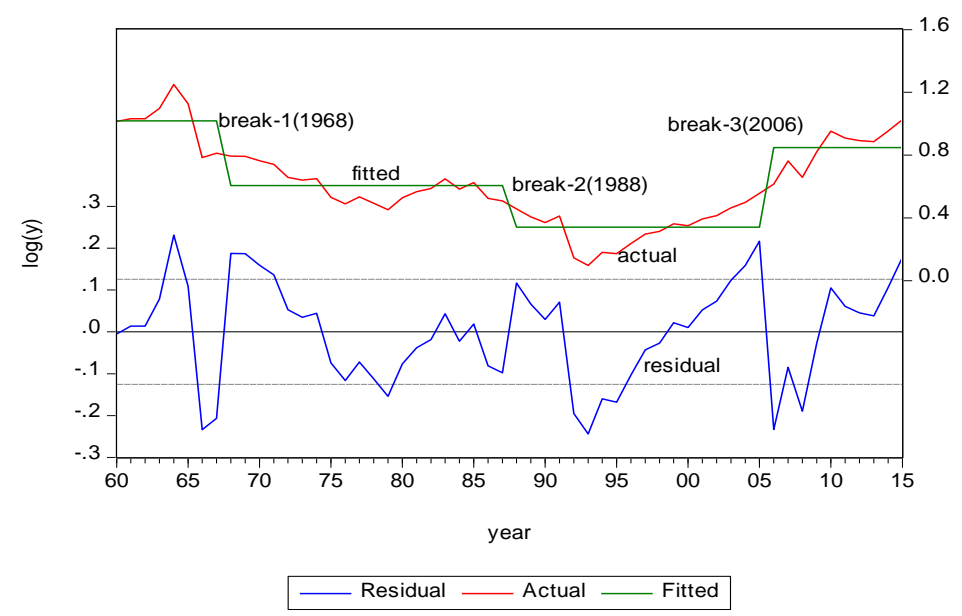

Figure 14. Structural breaks

Source: plotted by author. 
Short cycle implies:

1. Short cycle peak in $y_{t}$ if $\Delta y_{t}>0, \Delta y_{t+1}<0$.

2. Short trough in $y_{t}$ if $\Delta y_{t}<0$ and $\Delta y_{t+1}>0$.

3. Minimum length of the cycle equals to 2 years.

4. Minimum length of the each phase comprises 1 year.

And medium cycle implies:

1. Medium cycle peak in $y_{t}$ if $\Delta y_{t}>0, \Delta^{2} y_{t}>0$ and $\Delta y_{t+1}<0$ and $\Delta^{2} y_{t+1}<0$.

2. Medium trough in $y_{t}$ if $\Delta y_{t}<0, \Delta^{2} y_{t}<0$ and $\Delta y_{t+1}>0$ and $\Delta^{2} y_{t+1}>0$.

3. Minimum length of the cycle is 4 years.

4. Minimum length of the each phase is 2years.

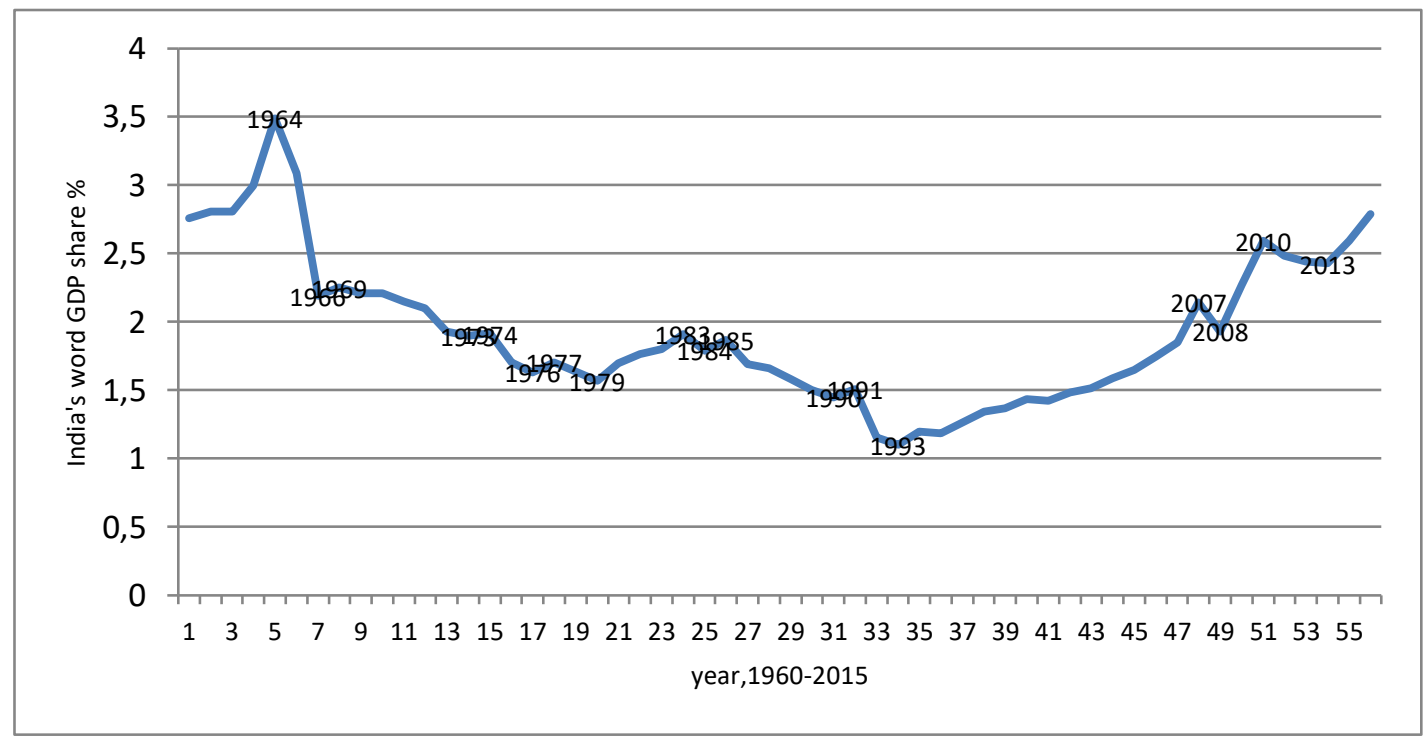

Figure 15. Peaks and troughs of India's world's GDP share

Source: plotted by author.

In Table 3, following Bartoletto, Chiarini, Marzano \& Piselli (2015), author computed peaks and troughs in both short and medium cycles from the series of India's world share of GDP from 1960 to 2015 where the duration of a downturn is the number of years between a peak and the next trough. Likewise, the duration of an upturn is the number of years from the trough to the subsequent peak. The amplitude measures the percentage change from peak to the next trough (downturn) or from a peak to the previous trough (upturn). The slope is the annual average (GM) growth rate. The slope measures the intensity of recovery or the voilence of a recession. The amplitudes and slopes have been fluctuating from time to time.

Table 3. Basic features of cycles: peaks, troughs, duration, amplitudes and slopes

\begin{tabular}{|l|c|c|c|c|c|c|c|c|c|c|}
\hline & \multicolumn{3}{|c|}{ Turning point } & \multicolumn{3}{c|}{ Duration(years) } & \multicolumn{2}{c|}{ Amplitude } & \multicolumn{2}{c|}{ Slope } \\
\cline { 2 - 12 } & Peak-1 & Peak-2 & trough & downturn & upturn & cycle & downturn & upturn & downturn & upturn \\
\hline \multirow{5}{*}{$\begin{array}{l}\text { Medium } \\
\text { cycles }\end{array}$} & 1964 & 1967 & 1966 & 2 & 1 & 3 & -31.26 & 2.736 & -15.63 & 2.736 \\
\cline { 2 - 13 } & 1967 & 1974 & 1973 & 6 & 1 & 7 & -18.67 & 1.05 & -3.12 & 1.05 \\
\cline { 2 - 12 } & 1974 & 1977 & 1976 & 2 & 1 & 3 & -10.62 & 4.55 & -5.31 & 4.55 \\
\cline { 2 - 12 } & 1977 & 1983 & 1979 & 2 & 4 & 6 & -8.54 & 21.80 & -4.27 & 5.45 \\
\cline { 2 - 12 } & 1983 & 1985 & 1984 & 1 & 1 & 2 & -6.35 & 4.18 & -6.25 & 4.18 \\
\cline { 2 - 12 } & 1985 & 1991 & 1990 & 5 & 1 & 6 & -22.43 & 4.21 & -4.48 & 4.21 \\
\cline { 2 - 12 } & 1991 & 2007 & 1993 & 2 & 14 & 16 & -26.65 & 94.71 & -13.32 & 6.76 \\
\cline { 2 - 11 } & 2007 & 2010 & 2008 & 1 & 2 & 3 & -9.43 & 34.23 & -9.937 & 17.11 \\
\hline
\end{tabular}

Source: calculated by author. 
The nature of cycles of the world's GDP share of India during 1960-2015 could be judged by the HodrickPrescott filter model which minimizes the variance of trend line around smooth series subject to a penalty that constraints second difference of smooth series .The penalty parameter lamda controls the smoothness of the variance series where larger is the Lamda the smoother is the variance. We assumed lamda is 1600 and found that smooth cycle has one distinct trough in a cycle which is shown in Figure 16.

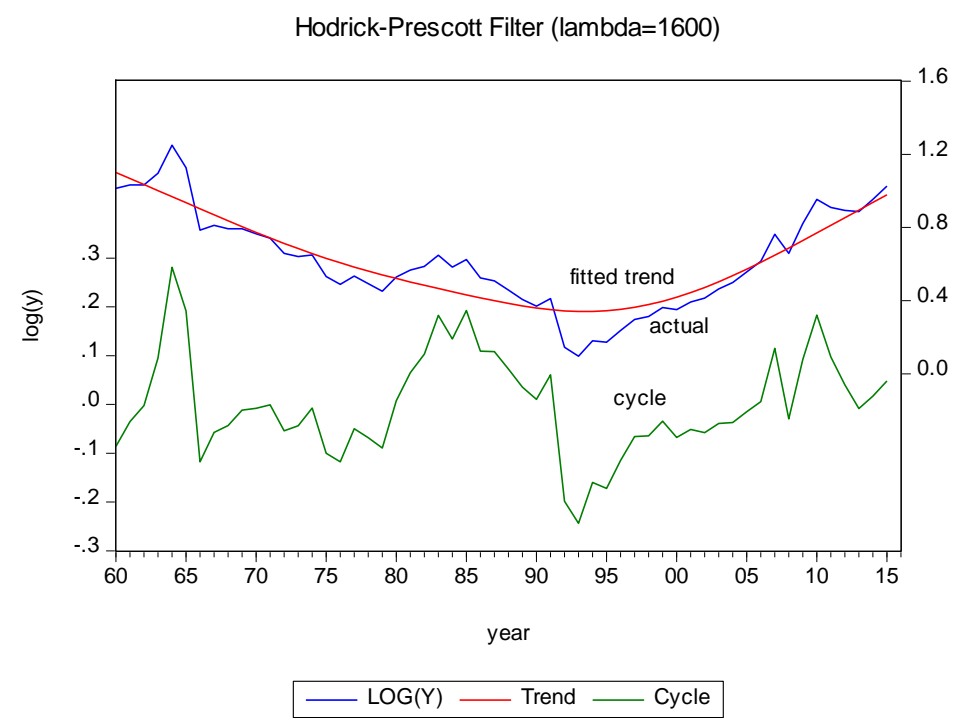

Figure 16. Smooth cycle

Source: plotted by author.

Hodrick-Prescott Filter asymmetric or symmetric tests clearly showed that cyclical phases have been turned smoothed cycles into two peaks and two troughs assuming lamda is 100 which is shown in Figure 17.

Asymmetric (time-varying) Filter

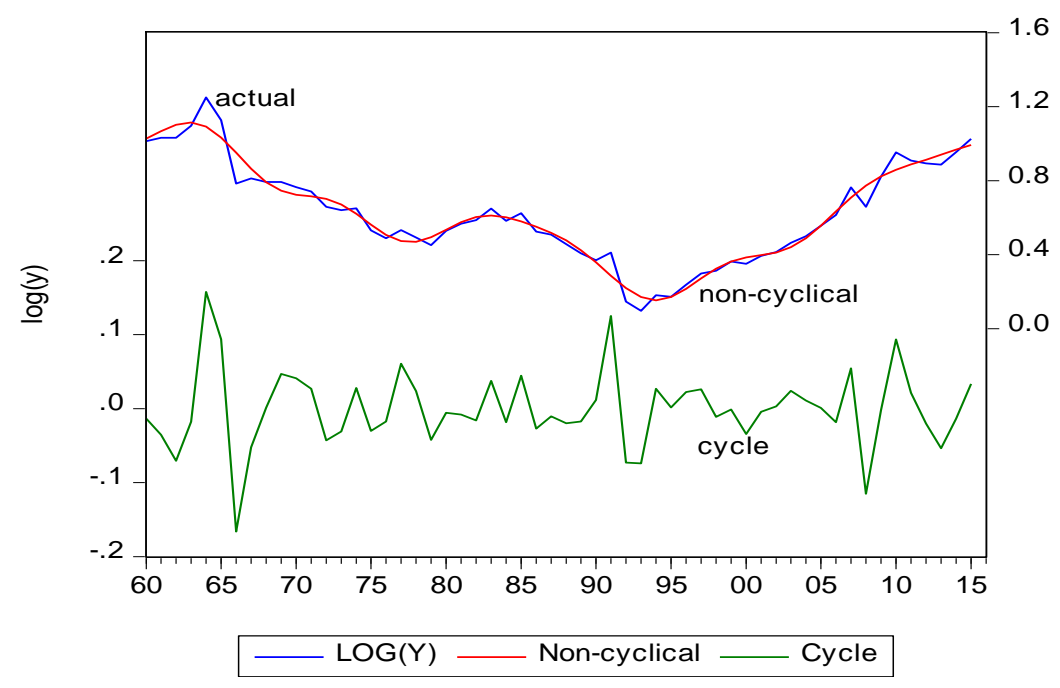

Figure 17. Asymmetric filter

Source: plotted by author.

In Figure 18, applying the symmetric test using fixed length Christiano-Fitzgerald model (2003), we found two smooth peaks and troughs each throughout the study period when after 1993 trough India's GDP share has been hiking unbreakably which was also observed in Bai-Perron test.

Frequency Response Function showed the peak of the amplitude and damping of the cycle (assuming one cycle per period). 

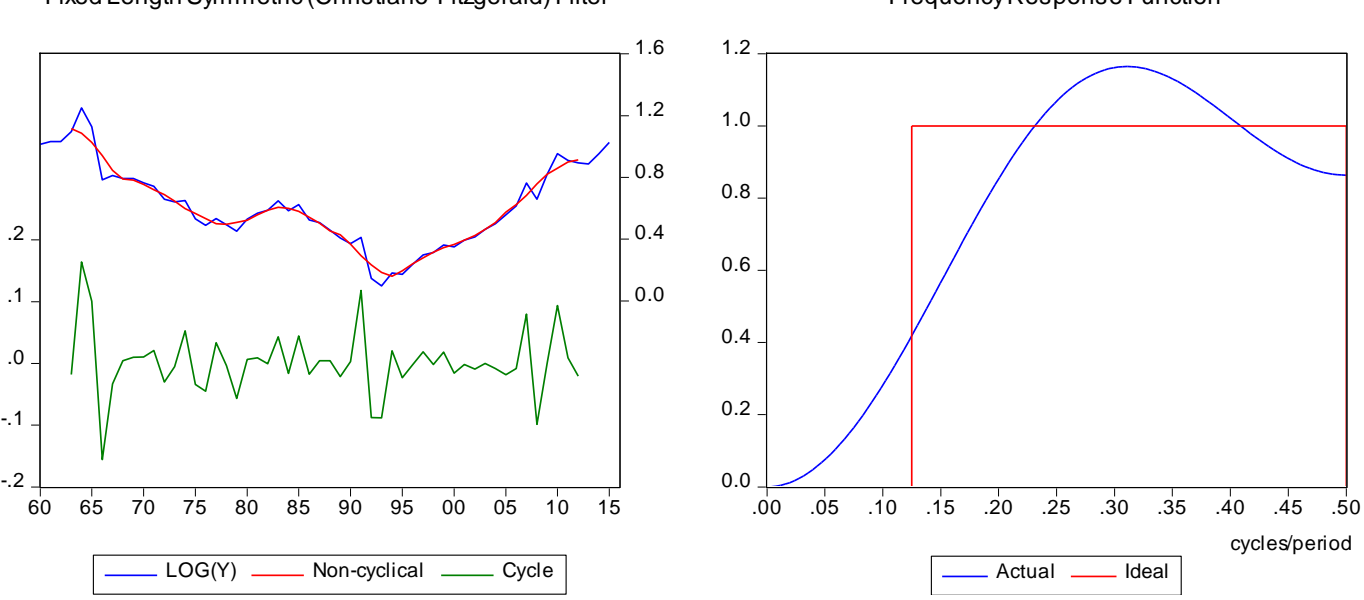

Figure 18. HP filter with symmetric test

Source: plotted by author.

Therefore, it is clear that India's international competitiveness in terms of GDP share is not favourable throughout the study period rather India's share showed cyclical patterns containing upswings and downswings or expansions and contractions which are required strong anticyclical fiscal and monetary policy with strong macro fundamentals to combat cycles. But, India had been confronting with current account deficits, high debt burdens, huge fiscal deficits, high inflation rate with unfavourable exchange rate since the planning periods which have been hindering India's development process and competitiveness.

\section{Limitations of the study}

The calculations of behavior of peaks, troughs, duration, amplitudes and slopes are essentially suitable for monthly or quarterly data where explanations will be more analytical and ARIMA $(1,1,1)$ forecast model is mostly applicable. Our study is limited to yearly data. How much international GDP share of India is influential in explaining sustainable developmental patterns is a great scope in this paper in future.

\section{Suggested policies}

The following are the important policies which can be conducted to enhance world's GDP share of India.

1. To increase world's GDP share, India needs to hike India's international export share.

2. India should reduce its external debts, negative current account balance as percent of GDP and fiscal deficit as percent of GDP respectively.

3. India's NEER and REER of Rupee should be downward trends.

4. India's openness index and the speed of financial integration should be enhanced gradually.

5. To check cyclical behavior of growth, India should apply appropriate expansionary and contractionary monetary and fiscal policy.

6. India's agri-exports have good prospect in which agricultural share in GDP should be given more importance so that India's World's GDP share may increase.

\section{Conclusion}

The paper concludes that international GDP share of India has decreased at the rate of $0.459 \%$ per year during 1960-2015 and declined exponentially at the rate $0.259 \%$ per year significantly. The growth rate of the GDP share is downward sloping significantly till 2030.It follows random walk without drift. Its AR(1) is stable, convergent and stationary. Forecast for 2035 of AR(1) is also converging. ARIMA $(1,1,1)$ is stable and nonstationary and suffers from AC and PAC problems. Its forecast model for 2035 is tending towards stationary level insignificantly. GARCH $(1,1)$ showed excessive volatility. It has two downward structural breaks in 1968 and 1988 and one upward break in 2006 which are significant. The paper also verified short and medium cycles to calculate peaks and troughs, duration of downturn and upturn, amplitude and slope of the cycles respectively. HP filter model makes the cycle more smooth with only one trough assuming lamda is 1600 but symmetric and asymmetric filter showed two peaks and two troughs. The frequency response function clarified its peaks and amplitude of cycle clearly. Suggested policy recommendations may increase India's GDP share in the offing. 


\section{References}

1. Agarwal, M. \& Ghosh, S. (2015, November). Structural Changes In The Indian Economy. Working Paper 465, Centre for Development Studies.

2. Bai, J. \& Perron, P. (2003). Critical values for Multiple Structural Change Tests. Econometrics Journal, 6, 72-78.

3. Bartoletto, S., Chiarini, B., Marzano, E. \& Piselli, P. (2015). Business cycles, credit cycles, and bank holdings of sovereign bonds: historical evidence for Italy 1861-2013. CES ifo Working Paper-5318, Munich.

4. Baxter, M. \& King, R.G. (1999).Measuring Business Cycles: Approximate Band-Pass filters for Economic Time Series. The Review of Economics and Statistics, 81(4), 575-593.

5. Bhowmik, D. (2017). Behaviour of India's GDP growth rate, FAME-1. Journal of Shri Shikshayatan College, Kolkata.

6. Bhowmik, D. (2017). Application of Econometrics in Economics. New Delhi: Synergy Books Pvt. Ltd.

7. Borio, C. (2012). The financial cycles and macroeconomics: What we learnt? BIS Working Paper No-395.

8. Bry, G. \& Boschen, C. (1971).Cyclical Analysis of Economic Time series: Selected procedures and Computer program. NBER Technical Working Paper, 21.

9. Burns, A.F. \& Mitchell, W.C. (1946).Measuring Business Cycles, NBER.

10. Christiano, L. J. and Fitzgerald, T.J. (2003).The band-pass filter. International Economic Review, 44(2), 435-465.

11. Dua, P. \& Banerji, A.(1999).An Index of Coincident Economic Indicators for the Indian Economy. Journal of Quantitative Economics, 15, 177-201.

12. Dua, P. \& Banerjee, A. (2012, January). Business and growth cycles in India. Centre for Development Studies, Delhi.

13. Enders, W. (2011). Applied Econometric Time Series. Wiley Student Edition.

14. Hodrick, R., \& Prescott, E.C. (1997). Post War US Business Cycles: An Empirical Investigation. Journal of Money, Credit and Banking, 29(1), 1-16.

15. Johansen, S.(1988).Statistical Analysis of Co-integrating Vectors. Journal of Economic Dynamics and Control, 12, 231-254.

16. Johansen, S.(1996). Likelihood-Based Inference in Co-integrated Vector Autoregressive Models. $2^{\text {nd }}$ edition, Oxford University Press.

17. Johansen, S. \& Juselius, K. (1990). Maximum likelihood estimation and co-integration with application to the demand of money. Oxford Bulletin of Economics and Statistics, 52(2), 169-210.

18. Juselius, K. (2006).The Cointegrated VAR Model. Oxford University Press.

19. Maddison, A. (2006). The World Economy: A Millennial Perspective. OECD, Paris.

20. Mohanty, J., Singh, B. \& Jain, R. (2003, January). Business cycles and leading indicators of industrial activity in India, MPRA Paper No. 12149.

21. Nayyar, D. (2008, June).China, India, Brazil and South Africa in the World Economy: Engines of growth? Discussion Paper, 2008/05.

22. Papola, T.S. (2012, April). Structural Changes In The Indian Economy: Emerging Patterns and Implications, ISID Working Papers-02.

23. Paul, J. \& Mas, E. (2016). The emergence of China and India in the global market. Journal of East-West Business, 22(1).

24. Virmani, A. (2005, January). India's Economic Growth History: Fluctuations, Trends, Break Points And Phases. Occassional Paper, Indian Council For Research On International Economic Relations.

25. Wolf, C., Larson, Eric V. \& Huang, M. (2011). China and India 2025: A Comparative Assessment. Rand National Defense Research Institute.

26. www.pwc.co.uk/economics (2015, February). The World in 2050: Will the shift in global economic power continue?

27. www.worldbank.org/statistics. 


\section{Appendix}

Table 1. GDP of World and India, \& India's GDP share in the world

\begin{tabular}{|c|c|c|c|}
\hline Year & $\begin{array}{l}\text { India's GDP in US\$ at current prices } \\
\text { (in trillion) }\end{array}$ & $\begin{array}{l}\text { World GDP in US\$ at current prices } \\
\text { (in trillion) }\end{array}$ & India's share in the world \% \\
\hline 1960 & 0.03768 & 1.367 & 2.7564 \\
\hline 1961 & 0.03992 & 1.422 & 2.8073 \\
\hline 1962 & 0.04290 & 1.528 & 2.8075 \\
\hline 1963 & 0.04927 & 1.645 & 2.9951 \\
\hline 1964 & 0.05747 & 1.802 & 3.1892 \\
\hline 1965 & 0.06060 & 1.963 & 3.0871 \\
\hline 1966 & 0.04667 & 2.129 & 2.1921 \\
\hline 1967 & 0.05101 & 2.265 & 2.25209 \\
\hline 1968 & 0.05402 & 2.444 & 2.2103 \\
\hline 1969 & 0.05947 & 2.692 & 2.2091 \\
\hline 1970 & 0.06352 & 2.956 & 2.1488 \\
\hline 1971 & 0.06853 & 3.264 & 2.0995 \\
\hline 1972 & 0.07272 & 3.763 & 1.93250 \\
\hline 1973 & 0.08701 & 4.585 & 1.8977 \\
\hline 1974 & 0.1013 & 5.288 & 1.9156 \\
\hline 1975 & 0.1002 & 5.889 & 1.7014 \\
\hline 1976 & 0.1045 & 6.407 & 1.63102 \\
\hline 1977 & 0.1236 & 7.247 & 1.70553 \\
\hline 1978 & 0.1397 & 8.529 & 1.6379 \\
\hline 1979 & 0.1557 & 9.91 & 1.5711 \\
\hline 1980 & 0.1896 & 11.156 & 1.6995 \\
\hline 1981 & 0.1969 & 11.448 & 1.764 \\
\hline 1982 & 0.2042 & 11.347 & 1.799 \\
\hline 1983 & 0.2221 & 11.606 & 1.9136 \\
\hline 1984 & 0.2159 & 12.047 & 1.7921 \\
\hline 1985 & 0.2366 & 12.67 & 1.8674 \\
\hline 1986 & 0.2534 & 14.995 & 1.6898 \\
\hline 1987 & 0.2859 & 17.098 & 1.6616 \\
\hline 1988 & 0.3018 & 19.099 & 1.5801 \\
\hline 1989 & 0.3012 & 20.05 & 1.5022 \\
\hline 1990 & 0.3266 & 22.548 & 1.4484 \\
\hline 1991 & 0.2748 & 23.876 & 1.5094 \\
\hline 1992 & 0.2933 & 25.35 & 1.1570 \\
\hline 1993 & 0.2842 & 25.794 & 1.1018 \\
\hline 1994 & 0.333 & 27.751 & 1.1981 \\
\hline 1995 & 0.3666 & 30.851 & 1.18829 \\
\hline 1996 & 0.3998 & 31.532 & 1.26791 \\
\hline 1997 & 0.4232 & 31.415 & 1.34669 \\
\hline 1998 & 0.4287 & 31.319 & 1.3688 \\
\hline 1999 & 0.4669 & 32.491 & 1.43701 \\
\hline 2000 & 0.4766 & 33.551 & 1.4205 \\
\hline 2001 & 0.494 & 33.346 & 1.4814 \\
\hline 2002 & 0.524 & 34.621 & 1.5135 \\
\hline 2003 & 0.6184 & 38.879 & 1.5905 \\
\hline 2004 & 0.7216 & 43.782 & 1.6481 \\
\hline 2005 & 0.8342 & 47.394 & 1.74588 \\
\hline
\end{tabular}


Table 1 (cont.). GDP of World and India, \& India's GDP share in the world

\begin{tabular}{|c|c|c|c|}
\hline Year & $\begin{array}{c}\text { India's GDP in US\$ at current prices } \\
\text { (in trillion) }\end{array}$ & $\begin{array}{c}\text { World GDP in US\$ at current prices } \\
\text { (in trillion) }\end{array}$ & India's share in the world \% \\
\hline 2006 & 0.9491 & 51.312 & 1.84966 \\
\hline 2007 & 1.239 & 57.757 & 2.14541 \\
\hline 2008 & 1.224 & 63.346 & 1.9322 \\
\hline 2009 & 1.365 & 60.046 & 2.2732 \\
\hline 2010 & 1.708 & 65.853 & 2.5936 \\
\hline 2011 & 1.816 & 73.17 & 2.48189 \\
\hline 2012 & 1.825 & 74.694 & 2.4433 \\
\hline 2013 & 1.863 & 76.77 & 2.4267 \\
\hline 2014 & 2.042 & 78.658 & 2.59604 \\
\hline 2015 & 2.074 & 74.292 & 2.79168 \\
\hline
\end{tabular}

Source: World Bank. 